\title{
UM DESCONHECIDO ENTRE NÓS: A HISTÓRIA E A CULTURA INDÍGENA NA SALA DE AULA
}

\author{
Cristiane Dias de Melo ${ }^{1}$
}

Uma roda. Daquelas que aprendemos quando criança. Daquelas que nossos ancestrais praticavam. Os adolescentes estavam sorridentes, alegres... ficam sempre assim quando há uma atividade fora da sala de aula. A ideia era sermos um pouco indígenas, em um círculo de energia pulsante, embalados pela canção

\author{
Sou Pataxó \\ sou Xavante e Cariri \\ Ianonami, sou Tupi \\ Guarani, sou Carajá \\ Sou Pancaruru \\ Carijó, Tupinajé \\ Potiguar, sou Caeté \\ Ful-ni-o, Tupinambá
}

Trata-se da música Chegança, composta e interpretada pelo artista Antônio Nóbrega. Se o leitor não identificou os nomes cantados na canção, esclareço. Essas denominações são algumas das mais de duzentas etnias indígenas existentes no território brasileiro, evidenciando a grande diversidade étnica e cultural que esses povos representam.

Essa diversidade, no entanto, é pouco conhecida pela sociedade brasileira. O estereótipo de um índio homogêneo, nu, com adornos de penas, morador da floresta e isolado do mundo chamado "civilizado", ainda é forte no imaginário da maioria dos brasileiros. Nas escolas, o Dia do Índio ainda é um dos poucos momentos em que esse personagem, integrante da tríade étnica que representa a formação do povo brasileiro em diversas narrativas que buscam uma identidade nacional, aparece. Porém, essa aparição fugaz acontece de forma genérica, com um ar de elemento exótico, em vias de extinção. Situação que, ao invés de trazer para o conhecimento dos alunos a história e a cultura desses povos, corrobora com os estereótipos criados ao longo da história do nosso país. Esse fato, aliado à minha paixão pela história e cultura de povos indígenas brasileiros, instigou-me a aprofundar esse tema nas minhas aulas ministradas para a $1^{\mathrm{a}}$ série do ensino médio na ETEC de Campo Limpo Paulista, escola onde atualmente leciono.

\section{O indígena na escola}

Em 2008, a Lei 11.645 incluiu no currículo oficial da rede de ensino nacional a obrigatoriedade da temática "História e Cultura Afro-Brasileira e Indígena". A lei, no entanto, não foi suficiente para uma ampla aplicação do ensino da História e Cultura Indígena de forma a romper com os estereótipos discutidos acima. ${ }^{2} \mathrm{O}$ que pode ser explicado, parcialmente, pela própria formação acadêmica dos professores de História, carente desse tema. Até mesmo a produção historiográfica relacionada ao tema não é muito expressiva e, se vem crescendo, é um processo ainda muito novo e dentro dos muros das universidades, não atingindo de forma efetiva aqueles que estão no chão da escola.

\footnotetext{
${ }^{1}$ E-mail: cristiasmelo@ hotmail.com.

${ }^{2}$ Sobre o ensino crítico da temática indígena e a importância da Lei 11.645/2008; nesse processo ver o artigo

"Povos indígenas: história, culturas e o ensino a partir da lei 11.645" de Edson Silva (2012).
} 
Esses limites ao conhecimento do professor sobre a temática indígena, todavia, não podem servir como eterna justificativa para cruzarmos os braços diante da necessidade latente de educarmos nossos alunos como agentes críticos e conscientes da necessidade do rompimento dos estereótipos eurocêntricos, ainda muito presente nas nossas matrizes curriculares. É necessário levar para a sala de aula e para outros espaços onde se pratica a educação a importância do papel protagonista dos povos indígenas como agentes históricos e culturais no processo de formação da nossa sociedade. Então surge a questão: como levar aos alunos um assunto tão urgente, mas ainda em construção na própria historiografia acadêmica?

O material mais comumente utilizado nas aulas de História nas escolas são os livros didáticos. Giovani José da Silva, ao analisar a História Indígena nos livros didáticos, aponta que é comum que, nessas obras, o indígena pertença exclusivamente ao passado, o que leva o aluno a ter a impressão de que eles estavam ausentes nos anos que se sucederam após a chegada dos europeus (SILVA, 2015). Um aspecto recorrente nesse tipo de material é a brevidade e a forma generalizada como a História Indígena é tratada, relegando a esses povos uma menor importância como integrantes da nossa sociedade e como atores da história do nosso país.

Há também a questão da escolha das imagens presentes nos livros didáticos. Em sua maioria, são reproduções de imagens feitas por ilustradores europeus que imprimiram, em suas obras, suas próprias impressões sobre a população nativa do território brasileiro. Conceitos como canibalismo, primitivismo e inocência estão constantemente presentes, reafirmando os estereótipos que se solidificaram no nosso ensino e também no imaginário de nossa sociedade.

A forma como os conteúdos dos livros didáticos são apresentados deve ser analisada de forma regular e crítica pelo professor. A despeito de um pequeno avanço nas abordagens, ainda há muito a ser superado, sendo necessário compreender que esses recortes, lacunas e equívocos presentes nesse tipo de material. Isso pode ser explicado, em grande parte, pelo mercado editorial e por ideologias dominantes, como nos alerta Circe Bittencourt no texto "Livros didáticos: entre textos e imagens" (BITTENCOURT, 2005).

Um olhar para a produção acadêmica nessa área é um caminho para começar a superar essas lacunas. Ainda que não tão expressivos se comparados a outros temas de pesquisas historiográficas, atualmente podemos observar os esforços crescentes de antropólogos e historiadores que vêm dialogando no sentido de criar uma "nova história indígena". Nos últimos anos, o paradigma da crônica da extinção dos povos indígenas vem perdendo espaço para essa produção. Infelizmente, essa incipiente reversão não se refletiu muito na produção dos livros didáticos, mas é um rico material de estudo para os professores que pretendem trabalhar a temática indígena em suas aulas. ${ }^{3}$

\section{Vídeos nas aldeias, uma escolha que deu certo}

Sendo os livros didáticos muito limitados para o foco que eu propunha em minhas aulas, ou seja, romper estereótipos e afirmar o indígena como agente histórico e cultural da História do Brasil de forma mais ampla e profunda, recorri a estudos de alguns textos da produção acadêmica comentada acima. Porém, não posso deixar de comentar o papel das lutas dos povos indígenas contemporâneos como um dos elementos propulsores dessa produção. As lutas por reconhecimento dos seus direitos evidenciaram o índio como protagonista histórico, político, cultural e social. Muitos pesquisadores passaram a pautar suas pesquisas também em favorecimento dessas reivindicações.

\footnotetext{
${ }^{3}$ John Monteiro discute profundamente a presença do indígena na historiografia brasileira. Ver os artigos "O desafio da história indígena no Brasil" (1995) e "Redescobrindo os índios da América portuguesa: Antropologia e história" (2001).
} 
E não pararam por aí. Muitos povos indígenas passaram a produzir os seus próprios materiais, com os seus próprios pontos de vista sobre a história da qual fizeram e fazem parte. Não aceitam mais que apenas o outro conte a história que lhes pertence. Muitas cartilhas de escolas indígenas atuais são produzidas por professores e pesquisadores indígenas, formados em universidades. Sites e vídeos criados pelos próprios indígenas já podem ser encontrados na internet. Esses materiais disponíveis facilitam o estudo do tema pelo professor, algo possível e necessário, pois não podemos ficar restritos a materiais tradicionais e limitadores de uma educação crítica e transformadora.

A partir dessa constatação, pesquisei, estudei e planejei as minhas aulas de História e Cultura Indígena no Brasil. Além da produção de slides para uma aula expositiva, procurei materiais que tratassem do tema a partir do ponto de vista dos próprios indígenas. Contar a história do lugar dos seus próprios agentes é uma metodologia que facilita a empatia, algo essencial na quebra de estereótipos. Optei por usar vídeos de um projeto chamado Vídeo nas aldeias, os quais são apresentados ou criados pelos próprios indígenas.

Criado em 1986 e estendido pelos anos subsequentes, Vídeo nas Aldeias (VNA) é precursor na área de produção audiovisual indígena no Brasil. O objetivo do projeto foi, segundo o texto de apresentação do site do projeto, "apoiar as lutas dos povos indígenas para fortalecer suas identidades e seus patrimônios territoriais e culturais, por meio de recursos audiovisuais e de uma produção compartilhada com os povos indígenas". ${ }^{4}$ No site, há um catálogo com mais de noventa vídeos disponíveis, trazendo muitas possibilidades didáticas.

Escolhi trabalhar com dois vídeos. Ambos fazem parte de uma série de vídeos apresentados pelo indígena Airton Krenak, da etnia Krenak. O primeiro vídeo, intitulado Índios, quem são eles?, é um convite à reflexão dos diversos estereótipos em relação ao índio, ainda muito presentes na mentalidade e no discurso da sociedade brasileira. Entrevistadas nas ruas, pessoas respondem àquilo que pensam sobre esses povos. Os termos "preguiçoso", "selvagem" e "extinto" são os mais recorrentes, evidenciando o extremo desconhecimento e preconceito ainda existente em relação aos povos indígenas. Há uma parte em que os próprios indígenas de diferentes etnias que também são entrevistados aparecem replicando essas respostas, o que mostra quem eles realmente são e o que fazem, derrubando muitos conceitos do senso comum. Ao levantar o debate com os alunos após a exibição do vídeo, surpreendi-me como se mostraram indignados diante depoimentos que trataram os indígenas como preguiçosos, improdutivos e desnecessários. A conversa foi rica e interativa e muitos alunos expuseram suas opiniões.

O segundo vídeo, chamado Outra história, é sobre a história de algumas etnias que vivem no Acre, porém contada a partir do ponto de vista dos próprios indígenas. Tempo da maloca, Tempo da correria, Tempo do cativeiro e Tempo dos direitos são as divisões cronológicas que compõem a narrativa histórica dessas etnias em um livro próprio, contrapondo-se à visão etnocêntrica da história, ainda tão presente no nosso currículo.

Ao pensarmos a história indígena a partir dos seus próprios agentes, muito do que achávamos conhecer se desconstrói e podemos passar a conhecer essa narrativa de um outro lugar. Nas aulas que apliquei, os alunos tiveram a oportunidade de observar esse outro lugar, essa outra história, acessando uma abordagem até então restrita a alguns setores do meio acadêmico. Também puderam observar o indígena diferente daquela figura estanque, atemporal. Conheceram o índio que estuda, que vê televisão, que usa celular e internet e que luta pelos seus direitos, inserido no contexto atual, como parte da população brasileira. Sem perder, no entanto, aspectos essenciais da sua cultura, ou seja, a resistência do seu modo de vida deixado como herança pelos seus ancestrais.

\footnotetext{
${ }^{4}$ Texto de apresentação do site Vídeos nas aldeias. Disponível em: 〈http://www.videonasaldeias.org.br/2009/vna.php?p=1〉. Acesso em: 20 mar. 2017.
} 
Como última atividade dessas nossas aulas, os alunos produziram livros infantis com reescrita e ilustrações de mitologias indígenas, bem como pesquisaram a etnia a qual pertencia cada mito. Também escreveram o que apreenderam das nossas aulas sobre História e Cultura Indígena e transcrevo a seguir alguns desses pequenos textos referentes às aulas realizadas entre os meses de junho e agosto de 2016.

Estudar a história indígena é importante, pois aprendemos mais sobre a história dos povos que nos antecederam e que existem até hoje, aprendemos a diferenciar historicamente as denominações sobre as etnias brasileiras indígenas e, principalmente, a quebrar os estereótipos construídos ao longo da história brasileira. (Victória e Thacyara)

É importante saber, pois dessa forma não nos baseamos em condições e visões impostas pela sociedade, tendo uma visão própria sobre os nossos antepassados e a história do Brasil. (Pedro e Thales)

A vida toda ouvimos o lado europeu da maioria das coisas, inclusive da história do nosso país. É de extrema importância quebrar esses estereótipos diante das culturas primitivas, pois são ele que geram o preconceito e a ignorância das demais culturas. (Aline e Victória)

O que pude observar nos olhos e nas falas dos meus alunos adolescentes foi uma vontade de poder conhecer mais e um interesse por outras histórias, outras culturas, tão próximas, e ao mesmo tempo, tão distantes de suas vidas. Provavelmente, o que consegui fazer nessas aulas foi apenas o início da transformação de paradigmas, mas tenho certeza de que foi um primeiro passo para romper com estereótipos que estimulam a ignorância, a intolerância e a injustiça.

\section{Referências}

BITTENCOURT, C. O saber histórico na sala de aula. São Paulo: Editora Contexto, 2005.

MONTEIRO, J. M. O desafio da história indígena no Brasil. In: SILVA, A. L.; GRUPIONI, L. D. B. (Org.). A temática indígena na escola. Brasília: MEC/MARI/UNESCO, 1995.

Redescobrindo os índios da América portuguesa: Antropologia e história, in O. AGUIAR, A.; J.; BATISTA, E.; PINHEIRO, J. (Org.). Olhares Contemporâneos: cenas do mundo em discussão na universidade. Fortaleza: Edições Demócrito Rocha, 2001.

SILVA, E. Povos indígenas: história, culturas e o ensino a partir da lei 11.645. Historien: revista de História, Petrolina, n. 7, 2012.

SILVA, G. J. Ensino de História Indígena. In: WITTMANN, L. T. (Org.) Ensino (d)e História Indígena. São Paulo: Autêntica Editora, 2015.

VÍDEO NAS ALDEIAS. Disponível em: 〈http://www.videonasaldeias.org.br >. Acesso em: 20 mar. 2017. 